\title{
Association of a Hydrophobically Modified Polyelectrolyte and a Block Copolymer Followed by Fluorescence Techniques
}

\author{
Telma Costa, ${ }^{* \dagger}{ }^{\dagger}$ Karin Schillén, ${ }^{*}$ Maria da G. Miguel, ${ }^{\dagger}$ Björn Lindman, ${ }^{\dagger, \dagger}$ and J. Seixas de \\ Melo*,† \\ Department of Chemistry, University of Coimbra, 3004-535 Coimbra, Portugal, and Division of Physical \\ Chemistry, Center for Chemistry and Chemical Engineering, Lund University, P.O. Box 124, \\ SE-22100 Lund, Sweden
}

Received: October 23, 2008; Revised Manuscript Received: January 1, 2009

\begin{abstract}
By using absorption and fluorescence (steady-state and time-resolved) techniques, the interaction between a poly(acrylic acid) (PAA), randomly grafted with pyrene (Py) units (PAAMePy55), and a triblock copolymer of poly(ethylene oxide) and poly(propylene oxide) $\left(\mathrm{EO}_{20} \mathrm{PO}_{68} \mathrm{EO}_{20}, \mathrm{P} 123\right)$ was investigated. From the fluorescence data, it is shown that upon addition of P123 a decrease of the (pyrene-pyrene, Py-Py) intramolecular association, i.e., a decrease of dynamic and static excimer formation, is observed. Time-resolved fluorescence data reveal the existence of two types of monomers (monomers that are able to form excimer, MAGRE, and isolated monomers) and two excimers. Addition of P123 causes also an increase of the amount of isolated Py monomers. The overall fluorescence data suggest that the PAAMePy55 and the P123 block copolymer associate strongly at low $\mathrm{pH}$, leading to the formation of P123 micelles surrounded by one PAAMePy55 chain, where the pyrene groups are located at the PPO/PEO interface of the P123 micelles. Steady-state fluorescence results also showed that an excess of P123 micelles in solution is required for the association to occur. At high $\mathrm{pH}$ (pH 9 and above) the situation is less clear. The steady-state (particularly in the $I_{1} / I_{3}$ ratio) and time-resolved fluorescence results indicate a contact between the pyrene groups and $\mathrm{PEO}$, which then would imply that there may be an interaction, but much weaker than at low $\mathrm{pH}$.
\end{abstract}

\section{Introduction}

The study of water-soluble polymers chemically modified by attaching hydrophobic groups (see, for example, refs 1-7) and their interaction with surfactants or other colloidal systems is currently gaining a renewed interest. . $^{1,35-11}$ Due to their strong tendency for intra- and/or intermolecular hydrophobic self-association and stabilization of colloidal suspensions, hydrophobically modified polymers, making use of their interaction with surfactants, are frequently used in pharmaceutical formulations, ${ }^{12,13}$ cosmetics, ${ }^{12,13}$ and in all modern water based paints. ${ }^{14,15}$

The knowledge on the kind of structures formed and on the mechanism operating in the self-assembly of hydrophobically modified polymers and their association with surfactants is thus of fundamental importance in order to correlate the nature of the hydrophobic structures with the macroscopic properties. ${ }^{16}$ To establish these correlations several techniques have been used, such as steady-state and time-resolved fluorescence, ${ }^{3,5,16-24}$ nuclear magnetic resonance (NMR), ${ }^{8}$ rheology, ${ }^{25}$ light scattering, ${ }^{24,26}$ microcalorimetry,,${ }^{9,27,28}$ etc. It is the ensemble of the information that can be obtained from these techniques that eventually allows a more complete characterization of the system.

Fluorescence techniques and the use of fluorescence probes have been shown to be powerful analytical tools in polymer chemistry. Among others they can provide valuable information on the mechanisms and kinetics of polymerization, the degree of curing and cross-linking, the oxidation, degradation, and also viscosity and permeability. Depending on the application the

\footnotetext{
* Corresponding authors. E-mail address: tcosta@qui.uc.pt (T.C.) sseixas@ci.uc.pt (J.S.d.M.).

$\dagger$ University of Coimbra.

${ }^{*}$ Lund University.
}

chosen probe must follow different screening criteria. ${ }^{29}$ Of particular interest to our work is the use of fluorescent probes which permit the characterization of microdomains formed by polymers, surfactants and polymer-surfactant systems, and conformational studies for example of hydrophobically modified polymers. ${ }^{30}$ The use of polymers tagged with fluorescent probes has been shown to be a successful way to follow their conformational behavior due to their high sensitivity to the characteristics of the microenvironment $(\mathrm{pH}$, temperature, molecular mobility, polarity, etc.). ${ }^{21-23,31}$ This is further reflected in their fluorescent characteristics, particularly if the fluorescent probe is able to form excimer, and in its ability to provide information on the nature of the associative processes involved.

In dilute solutions, interactions take place between the segments of the polymer molecule and polymer-polymer interactions are absent. ${ }^{32}$ The formation of an intramolecular excimer is not a result of a translational process but results from an internal rotation of the polymer backbone during the lifetime of the excited monomer. ${ }^{33}$ This process depends, among other factors, on the flexibility and length of the hydrophobic chain, the solvent, medium viscosity, and temperature. The intramolecular association of poly(acrylic acid), PAA, randomly grafted with pyrene and naphthalene units (PAAMePy and PAAMeNp polymers, respectively), in aqueous solutions, using steady-state and time-resolved fluorescence data, has been previously investigated..$^{3,21-23}$ The behavior of these polymers in solution mainly results from the balance between hydrophobic (pyrenepyrene or naphthalene-naphthalene) association and ( $\mathrm{pH}$ dependent) intramolecular electrostatic repulsive interactions.

It is well established that triblock copolymers of poly(ethylene oxide) (PEO) and poly (propylene oxide) (PPO), with a middle PPO block and two PEO end blocks (PEO-PPO-PEO), behave 
in many ways like normal hydrocarbon surfactants and tend to form micelles in aqueous solution. ${ }^{15}$ The PEO-PPO-PEO copolymers self-assemble to form micelles because of the limited and temperature dependent solubility of the PPO block in water. ${ }^{34-38}$ The block copolymer micelle consists of a core of mainly the hydrophobic PPO blocks with a low water content surrounded by a water-swollen corona of PEO-blocks. ${ }^{15}$ However, the critical micelle concentration $(\mathrm{cmc})$ of the PEO-PPOPEO block copolymers is less sharp compared to ordinary surfactants due to the copolymer polydispersity and therefore the unimer-to-micelle transition occurs over a broad concentration range. The $\mathrm{cmc}$ is also very dependent on the temperature, i.e., the cmc value can change several orders of magnitude within a small range of temperatures. Hence, the micelle formation is induced with increasing temperature due to the temperature dependence of the $\mathrm{PO}-\mathrm{PO}, \mathrm{EO}-\mathrm{EO}$, and $\mathrm{EO}-\mathrm{PO}$ interactions. The $\mathrm{PO}-\mathrm{PO}$ attractive forces will dominate over the EO-EO repulsion, and micelles will form at some specific temperature. Polymers containing an - $\mathrm{OCCO}-$ sequence, like PEO or PPO, have different conformational states with different polarities. ${ }^{39}$ At low temperature, the polar class dominates, since it has the lowest energy, with favorable polymer-water contacts. At high temperature, the nonpolar states dominate with less favorable polymer-water interaction as a consequence. Such polymer-water systems display a lower critical solution temperature (LCST), above which there is liquid-liquid phase separation. ${ }^{15}$

The micelle formation of the $\mathrm{EO}_{20} \mathrm{PO}_{68} \mathrm{EO}_{20}$ copolymer (denoted P123) and the interaction with ionic (SDS and CTAC) and nonionic $\left(\mathrm{C}_{12} \mathrm{EO}_{6}\right)$ surfactants was previously studied using differential scanning and titration calorimetry, static and dynamic light scattering (DLS), small-angle X-ray scattering, NMRdiffusometry, and rheology. ${ }^{40-45}$ The DSC ${ }^{42,43}$ and surface tension measurements ${ }^{46}$ show that the P123 block copolymer is in the micellar form at $40{ }^{\circ} \mathrm{C}$, when a concentration of, respectively, $3.48 \times 10^{-7}$ and $5.2 \times 10^{-7} \mathrm{M}$ is reached, in aqueous solution.

In the literature, numerous investigations on the subject of complex formation between poly(carboxylic acids) and nonionic PEO exist. The complex formation was always discussed in the terms of hydrogen bonding of the proton-accepting PEO starting with one of the early works by Bailey, Jr., et al., ${ }^{47}$ e.g. in the review article, ref 48 . It should be stressed that in these systems there is, of course, interplay between electrostatic and hydrophobic interaction forces as well as hydrogen bonding. The stability and the structure of the interpolymer complexes between poly(carboxylic acids), such as PAA or poly(methylacrylic acid) (PMAA) and nonionic polymers, such as PEO, depend on the $\mathrm{pH}$, the ionic strength, the molecular weight of the polymers, and whether hydrophobic groups have been introduced or not. ${ }^{49-51}$ According to these investigations, if the molecular weight of PEO or the PAA is too low or if the $\mathrm{pH}$ is above a certain critical value, which depends on the nature of the poly(carboxylic acid), no interpolymer complexes are formed. It has also been confirmed by calorimetric measurements on different polymer pairs that hydrophobic interactions contribute to the intermolecular complex formation in aqueous solution. ${ }^{48}$ The interpolymer complexes between PMAA and $\mathrm{PEO}$, which were stable at low $\mathrm{pH}$ and disintegrate at $\mathrm{pH} \approx 6$ according to the specific viscosity measurements, became more stable when hydrophobic 2-acetoxybenzoate groups were introduced on the PEO chain. ${ }^{51}$ The interpolymer complexation of PAA with poly(acrylamide) and hydrolyzed poly(acrylamide) was investigated by using fluorescence spectroscopy and vis-

\section{SCHEME 1}
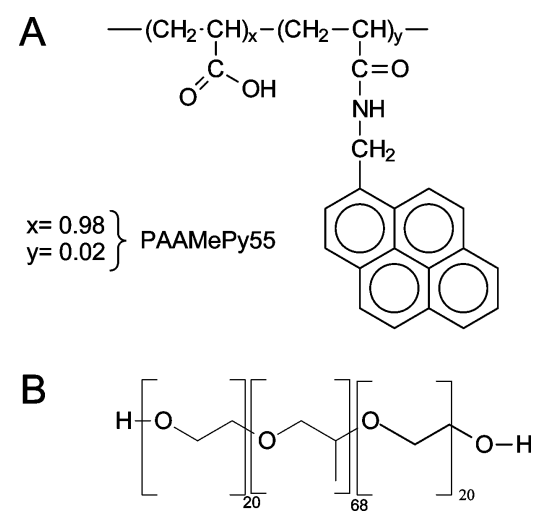

cosimetry. ${ }^{52}$ In that study, both the molecular weight of PAA, $\mathrm{pH}$, and the ionic strength were found to influence the complex formation.

The purpose of this study was to investigate the interaction between PAA labeled with hydrophobic pyrene groups PAAMePy and the PEO-PPO-PEO triblock copolymer P123, which contains both nonionic polar PEO and hydrophobic PPO groups, as a function of $\mathrm{pH}$ in the aqueous medium by means of steadystate and time-resolved fluorescence spectroscopy. This is the first study, in a series of two, where the second will also employ dynamic light scattering to complement the fluorescence results in order to obtain information about the structure of the PAAMePy55-P123 complexes formed under various conditions. ${ }^{53}$

\section{Experimental Section}

Polymers. Poly(acrylic acid) (PAA) with a nominal molecular weight of $150000 \mathrm{~g} / \mathrm{mol}$ was purchased from Wako Chemicals as a $25 \%$ water solution. The pyrene-labeled PAA sample was kindly provided by Dr. Dan Anghel, and the synthesis followed the same route as described elsewhere. ${ }^{2}$ All chemicals used in the syntheses were of reagent-grade. The amounts of pyrene in the sample was determined both by ultraviolet (UV) absorption measurements using 1-pyrenylmethylamine hydrochloride as a model compound and by ${ }^{1} \mathrm{H}$ nuclear magnetic resonance $\left({ }^{1} \mathrm{H}\right.$ NMR) measurements in deuterium oxide. The Py content of labeled PAA polymer was determined to $[\mathrm{Py}]_{\mathrm{UV}}=1.82 \mathrm{~mol}$ $\%\left(2.5 \times 10^{-4} \mathrm{~mol} / \mathrm{g}\right.$ polymer $)$ and $[\mathrm{Py}]_{\mathrm{NMR}}=2.05 \mathrm{~mol} \%(2.9$ $\times 10^{-4} \mathrm{~mol} / \mathrm{g}$ polymer), which corresponds to 55 monomers per chromophore, respectively. This sample is denoted PAAMePy55; see Scheme 1A.

The PEO-PPO-PEO triblock copolymer was a kind gift from BASF Corporation, Performance Chemicals, Mount Olive, New Jersey, and used without further treatment. The copolymer, presented in Scheme 1B, has the average composition $\mathrm{EO}_{20} \mathrm{PO}_{68} \mathrm{EO}_{20}$ (denoted P123, where P stands for "paste" and 3 for $30 \mathrm{wt} \%$ of PEO) and a nominal molar mass of 5750 $\mathrm{g} / \mathrm{mol}$. The poly(ethylene oxide) (molar mass $200 \mathrm{~g} / \mathrm{mol}$ ) and the poly(propylene oxide) (molar mass $1000 \mathrm{~g} / \mathrm{mol}$ ) polymers (Aldrich) and pyrene (99\% Fluka) were used as received.

Sample Preparation. The PAAMePy55-P123 mixed solutions were prepared with a constant PAAMePy55 polymer concentration $\left(5 \times 10^{-7} \mathrm{M}\right)$ and varying the P123 copolymer concentration. The solutions were kept in the fridge overnight, and prior to the measurements, they were equilibrated at room temperature for at least $20 \mathrm{~min}$ and thereafter kept at the measuring temperature $\left(40{ }^{\circ} \mathrm{C}\right)$ for at least $20 \mathrm{~min}$.

The water used in the solutions was twice distilled and passed through a Millipore apparatus. The measured $\mathrm{pH}$ values were 


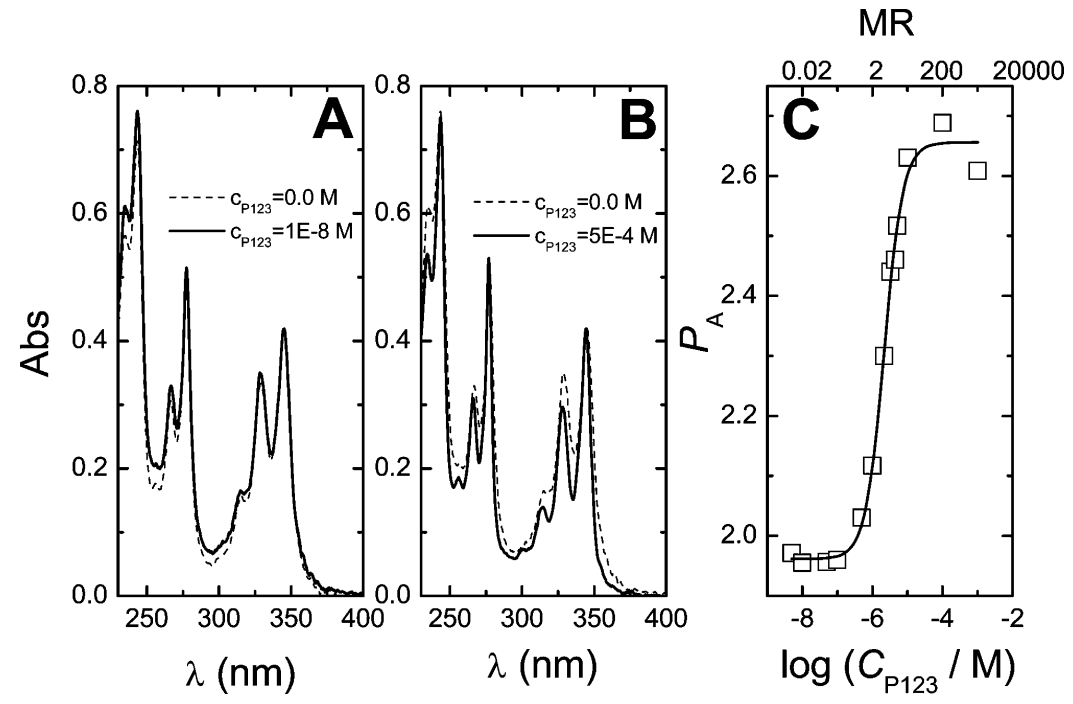

Figure 1. Absorption spectra of PAAMePy55 in aqueous solution, with and without $\mathrm{P} 123$, at $\mathrm{pH} 3.6$ (A and B), and dependence of the $P_{\mathrm{A}}$ parameter on P123 concentration (C). The solid line in $\mathrm{C}$ is a guide to the eye.

obtained with a Crison micropH 2000 and adjustments of the hydrogen ion concentration of the solutions were made with diluted $\mathrm{HCl}$ and $\mathrm{NaOH}$ solutions. The PAAMePy55 concentration in the different solutions is well below the critical value for coil overlap, $C^{*}$, and intermolecular chain contacts are therefore improbable in homogeneous solutions; the low optical density of the used samples prevents self-absorption or inner filter effects. $C^{*}$ was estimated to be $10 \mathrm{~g} / \mathrm{L}$ in ref 3 .

Equipment. Absorption and fluorescence spectra were recorded on Shimadzu UV-2100 and Jobin-Ivon SPEX Fluorog 3-22 spectrometers, respectively. All the fluorescence spectra were corrected for the wavelength response of the system.

Fluorescence decays were measured using a home-built TCSPC apparatus ${ }^{54}$ with an Horiba-JI-IBH nanoLED $\left(\lambda_{\text {exc }}=\right.$ $339 \mathrm{~nm}$ ) as the excitation source, Jobin-Ivon monochromator, Philips XP2020Q photomultiplier, and Canberra instruments TAC and MCA. The fluorescence decays were analyzed using the modulating functions method of Striker. ${ }^{55}$ Temperature control was achieved using a home-built system based on cooled nitrogen and electric heating, which is automatically controlled by the difference between the input temperature value and the real sample temperature, determined with a PT100 thermometer.

\section{Results}

The interaction between the P123 block copolymer and the PAAMePy55 polymer was investigated by fluorescence techniques for different excitation wavelengths and $\mathrm{pH}$ values. The used concentrations were $5 \times 10^{-7} \mathrm{M}$ for the PAAMePy55 polymer and ranged from $1 \times 10^{-8}$ to $1 \times 10^{-3} \mathrm{M}$ for the P123 block copolymer, which includes the cmc of P123 in water at $40{ }^{\circ} \mathrm{C} .{ }^{42,43,46}$

Absorption Spectra. The PAAMePy55 polymer absorption spectrum shows the characteristic vibronically resolved spectra of the pyrene chromophore (Figure 1A and B). We have previously reported that the photophysical properties of this polymer reflect the contributions of the isolated pyrene, Py, probe (monomers), and of preformed Py $\cdots$ Py aggregates also designated as ground-state dimers (GSD). When the relative monomer vs GSD contribution is modified, it is reflected in variations in the relative positions, the intensities of the vibronic bands, and the broadening of the absorption (and excitation) spectra of the PAAMePy55 polymer. ${ }^{21}$ The presence and relative contribution of GSD can therefore be detected by changes in the absorption spectra of these polymers, usually defined by the $P_{\mathrm{A}}$ and $\lambda_{\mathrm{abs}}^{\max }$ parameters. ${ }^{21,31}$ The $P_{\mathrm{A}}$ parameter is the ratio between the absorption values at maximum and the minimum, i.e., the peak-to-valley ratio, relative to the lower energetic electronic transition, $\mathrm{S}_{0} \rightarrow \mathrm{S}_{2}$. The $\lambda_{\mathrm{abs}}^{\max }$ parameter corresponds to the maximum absorption wavelength in this same transition band. ${ }^{21,31}$ Figure $1 \mathrm{C}$ shows the dependence of the $P_{\mathrm{A}}$ parameter with the addition of P123 block copolymer. As can be seen, the $P_{\mathrm{A}}$ values do not vary appreciably until a certain P123 concentration is reached $\left(\sim 1 \times 10^{-7} \mathrm{M}\right.$, at $\mathrm{pH} 3.6$ and room temperature) beyond which it sharply increases, thus showing a decrease of the ground-state association. These observations give a clear indication that PAAMePy55 and P123 associate in aqueous solution.

Steady-State Fluorescence. The emission spectra of PAAMePy55 in aqueous solution in the absence or presence of P123 displays the characteristic pyrene emission with a shorter wavelength vibronically resolved band (monomer) coexisting with a broad longer wavelength emission band (excimer); see Figure 2A. The addition of P123 to the solution leads to a decrease in the excimer emission which, nevertheless, is always present as seen by comparison with the pyrene (monomer) emission spectrum (Figure 2A).

The excimer-to-monomer fluorescence intensity ratio $\left(I_{\mathrm{E}} / I_{\mathrm{M}}\right)$ can be used to directly observe changes in the pyrene labeled PAA chain conformation and consequently on the level of interaction with the P123 block copolymer. Figure 2B shows, at three different $\mathrm{pH}$ values and at $40{ }^{\circ} \mathrm{C}$, the dependence of the $I_{\mathrm{E}} / I_{\mathrm{M}}$ ratio on the $\mathrm{P} 123$ concentration. At acidic $\mathrm{pH}$ values, the same sigmoidal-like curve can be observed, the exception being at $\mathrm{pH} 9$. At low $\mathrm{P} 123$ concentrations, the $I_{\mathrm{E}} / I_{\mathrm{M}}$ values are high and constant until a certain concentration is reached; from this concentration on, a sudden decrease of the $I_{\mathrm{E}} / I_{\mathrm{M}}$ ratio occurs and a subsequent new plateau at higher P123 concentrations is attained for this ratio. From these observations the existence of association between the two polymers seems clear and that a complex, where the PAAMePy55 polymer has the pyrene groups attached to P123 micelles, is formed. The concentration at which the P123 begins to associate strongly, and therefore to induce conformational changes in PAA chain, is obtained from the maximum of the negative value of the first derivative in the 


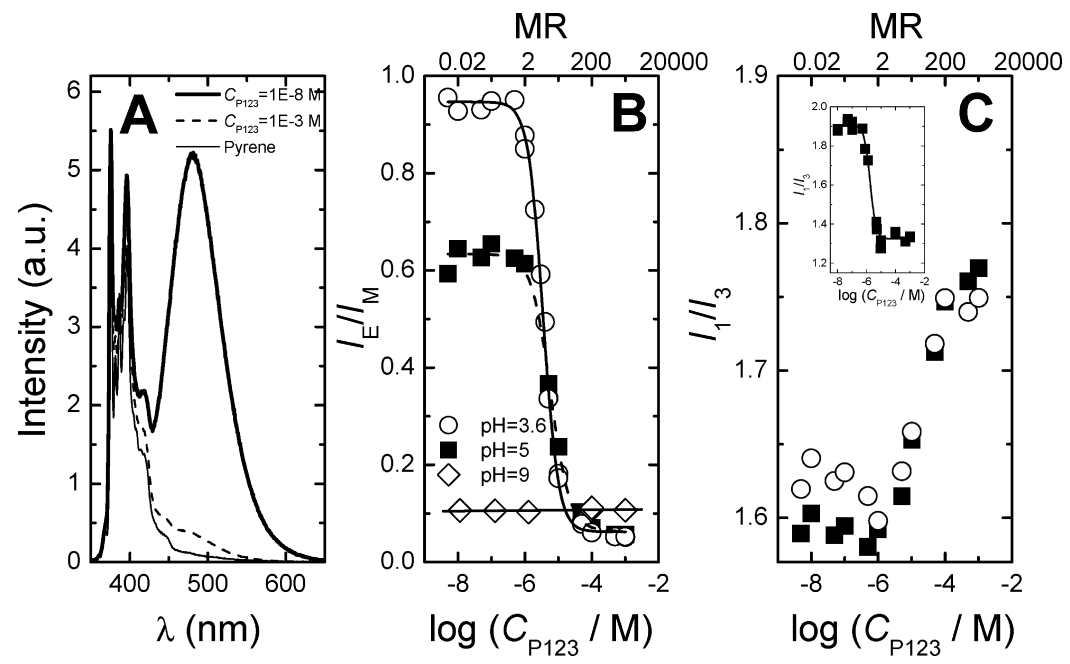

Figure 2. Emission spectra of pyrene and PAAMePy55 in the presence of P123 (A). Variation of the $I_{\mathrm{E}} / I_{\mathrm{M}}(\mathrm{B})$ and $I_{1} / I_{3}(\mathrm{C})$ ratios with the P123 concentration at different $\mathrm{pH}$ values and at $40^{\circ} \mathrm{C}$. The variation of the $I_{1} / I_{3}$ ratio of the pure $\mathrm{P} 123$ block copolymer, using pyrene $\left(C=4 \times 10^{-7}\right.$ $\mathrm{M})$ as an external probe is shown as inset in $\mathrm{C}$.

$I_{\mathrm{E}} / I_{\mathrm{M}}$ ratio vs $C_{\mathrm{P} 123}\left[\mathrm{~d}\left(I_{\mathrm{E}} / I_{\mathrm{M}}\right) / \mathrm{d}\left(\log _{10} C_{\mathrm{P} 123}\right)\right]$ plots. ${ }^{3}$ At $40{ }^{\circ} \mathrm{C}$, the obtained values are $3.5 \times 10^{-6}$ and $6.7 \times 10^{-6} \mathrm{M}$, at $\mathrm{pH}$ 3.6 and 5, respectively. Above this concentration, a new plateau is attained, corresponding to the saturation point, i.e., to the situation where each PAA chain associates with P123 micelles and a further increase in the P123 concentration leads to free P123 micelles in aqueous solution. This has been confirmed by DLS measurements (see ref 53). The saturation points at $\mathrm{pH}$ 3.6 and 5 are at P123/PAAMePy55 molar ratios $\left(n_{\mathrm{P} 123} / n_{\mathrm{PAAMeP} y 55}\right.$ $\equiv$ MR) $\sim 200$ and $\sim 1000$, respectively, which correspond to P123 concentrations of $1 \times 10^{-4}$ and $5 \times 10^{-4} \mathrm{M}$.

From the pyrene polarity-ruler parameter, that is the variation of the intensity ratio between the first $\left(I_{1}\right)$ and the third $\left(I_{3}\right)$ vibronic bands of the monomer emission $\left(I_{1} / I_{3}\right.$ ratio), one can get further information concerning the polarity environment felt by PAAMePy55 pyrene groups and, consequently, on the type of polymer-polymer interactions. The data presented in Figure $2 \mathrm{C}$ is for $\mathrm{pH} 3.6$ and 5 ; in both cases, we may observe an increase in the $I_{1} / I_{3}$ ratio (increase in the polarity felt by the Py probe) $)^{21,56}$ with $C_{\mathrm{P} 123}$. An opposite behavior is observed with pyrene in a solution of P123 block copolymer. In fact, above the $\mathrm{cmc}$, that is, when the pyrene chromophore is incorporated inside the P123 micelle core, the $I_{1} / I_{3}$ ratio is now $\sim 1.32$, at 40 ${ }^{\circ} \mathrm{C}$ (inset of Figure 2C). At pH 9 and $C_{\mathrm{P} 123}=1 \times 10^{-3} \mathrm{M}$, a slight increase in the $I_{1} / I_{3}$ ratio (from 1.88 in pure water to 2.0 ) is observed; however, this seems to give further confirmation that few pyrene groups are in contact with either the P123 block copolymer micelles or the unassociated diblock impurities inherent to the commercially available block copolymers (see below). In any of these cases, we may conclude that the intermolecular association between PAAMePy55 and P123 is strongly reduced at alkaline $\mathrm{pH}$ values.

Additional information regarding the level of interaction between the two polymers and particularly on the level of GSD formed, within the PAAMePy55 polymer, can be seen from the emission (with different excitations) and excitation spectra. ${ }^{21}$ The variation of the $I_{\mathrm{E}} / I_{\mathrm{M}}$ ratio as a function of P123, obtained with different excitation wavelengths $\left(\lambda_{\text {exc }}\right)$, is presented in Figure 3. As can be seen, in the low P123 concentration regime (at concentrations below the inflection point of the sigmoidal curve) at all $\mathrm{pH}$ values, an increase in the $\lambda_{\text {exc }}$ is accompanied by an increase of the $I_{\mathrm{E}} / I_{\mathrm{M}}$ ratio. However, in the high P123 concentration regime (above the inflection point) at $\mathrm{pH} 3.6$ and

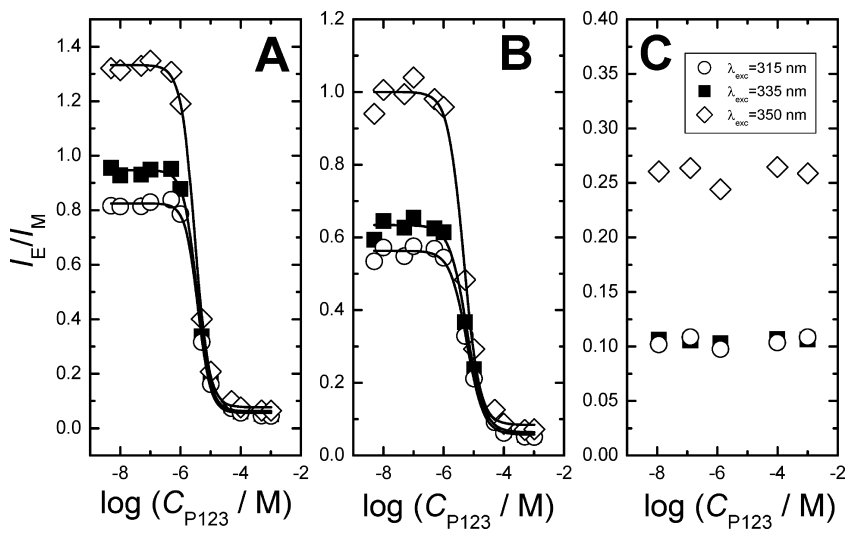

Figure 3. Dependence of the excimer-to-monomer $\left(I_{\mathrm{E}} / I_{\mathrm{M}}\right)$ ratio on the concentration of the P123 block copolymer in an aqueous solution of PAAMePy55 obtained at three different excitation wavelengths at 40 ${ }^{\circ} \mathrm{C}: 315(\mathrm{O}), 335(\boldsymbol{\square})$, and $350 \mathrm{~nm}(\diamond)$, at pH $3.6(\mathrm{~A}), \mathrm{pH} 5(\mathrm{~B})$, and pH 9 (C).

5 , there is no dependence on the excitation wavelength. These results show that, as a result of the association with P123, the level of ground-state association within the PAAMePy55 polymer is significantly reduced at high P123 concentrations. At $\mathrm{pH} 9$, there is only a constant shift of the emission intensity for $\lambda_{\mathrm{exc}}=350 \mathrm{~nm}$ (Figure 3C). This indicates that the PAAMePy55 chain is unaffected by the presence of the P123 micelles.

As was previously mentioned, the differences in the excitation spectra, when collected in the monomer $\left(\lambda_{\mathrm{em}}=374 \mathrm{~nm}\right)$ and excimer $\left(\lambda_{\mathrm{em}}=520 \mathrm{~nm}\right)$ emission regions, can also be used as an evidence for the presence of GSD (Figure 4). ${ }^{21,57}$ If the excimer formation occurs only through a dynamic mechanism, the excitation spectra should overlap, i.e., no shift $\left(\Delta \lambda_{2}=0\right)$ and there would be no difference in the $P_{\mathrm{M}}$ and $P_{\mathrm{E}}$ values $^{57}$ (which are the analogous to the $P_{\mathrm{A}}$ value in the fluorescence excitation spectra) when collected at the monomer and excimer emission wavelengths, respectively. These data, $\Delta \lambda_{2}, P_{\mathrm{M}}, P_{\mathrm{E}}$, and $P_{\mathrm{E}}-P_{\mathrm{M}}$, obtained for PAAMePy55 with different P123 concentrations are summarized in Table 1. The incremental addition of P123 leads to a decrease of the $\Delta \lambda_{2}$ values and to an increase of the $P_{\mathrm{E}}$ also mirrored by a decrease of the $P_{\mathrm{E}}-$ $P_{\mathrm{M}}$ difference.

The formation of higher-order complexes, i.e., involving more than one PAAMePy55 chain, was also checked. Indeed, 

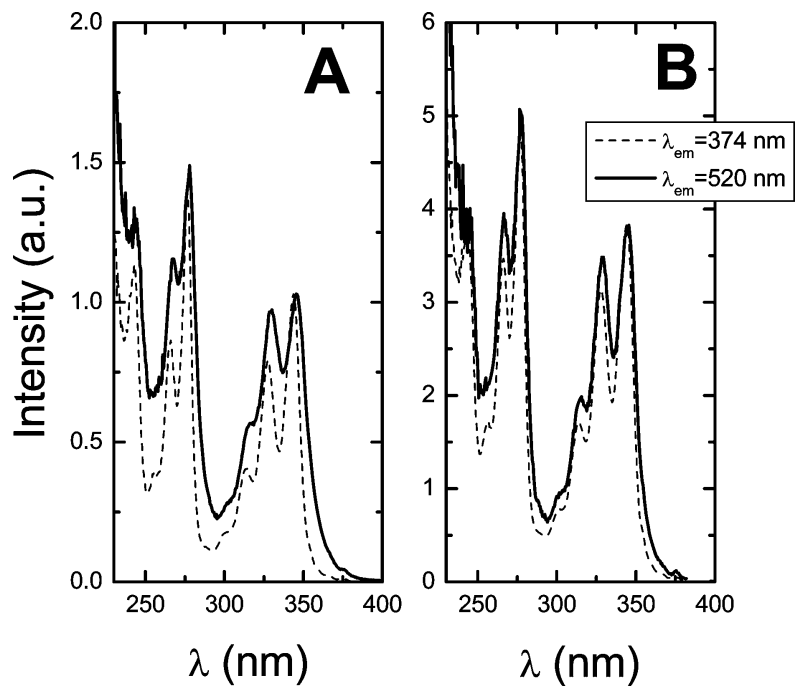

Figure 4. Excitation spectra collected at the monomer $\left(\lambda_{\mathrm{em}}=374\right.$ $\mathrm{nm})$ and excimer $\left(\lambda_{\mathrm{em}}=520 \mathrm{~nm}\right)$ emission wavelength, for a PAAMePy55 solution with $1 \times 10^{-8}$ (A) and $1 \times 10^{-3} \mathrm{M}(\mathrm{B})$ of P123, at $\mathrm{pH} 3.6$ and at $40{ }^{\circ} \mathrm{C}$.
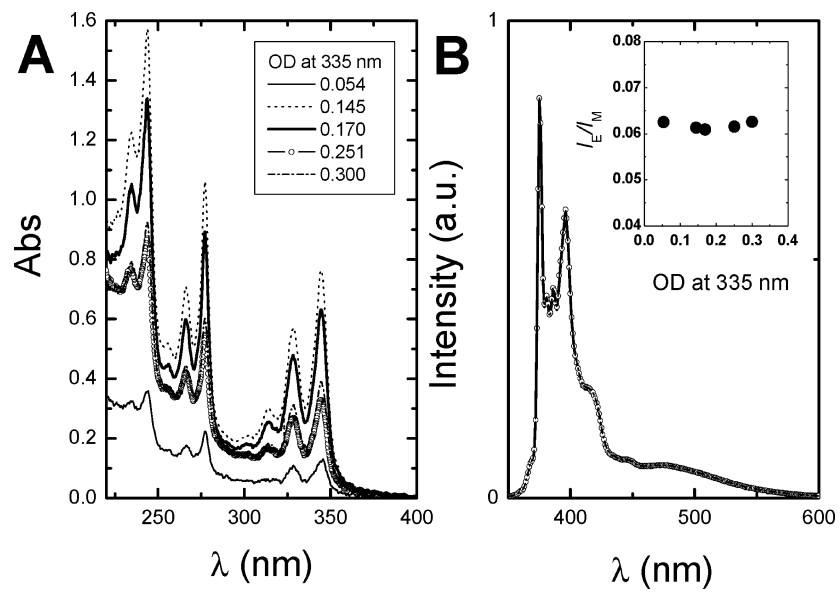

Figure 5. Absorption (A) and normalized fluorescence spectra (B) for a P123-PAAMePy55 mixed solution with a PAAMePy55 concentration ranging from $1.3 \times 10^{-7}$ to $7.5 \times 10^{-7} \mathrm{M}$ and a fixed $\mathrm{P} 123$ concentration $\left(1 \times 10^{-3} \mathrm{M}\right)$, at $\mathrm{pH} 3.6$ and $40{ }^{\circ} \mathrm{C}$. Shown as insets are the different $I_{\mathrm{E}} / I_{\mathrm{M}}$ ratio values as a function of the optical density (OD) at $335 \mathrm{~nm}$.

intermolecular interactions between PAAMePy55 polymer chains in water are not likely to occur at this concentration. However, it was observed that the presence of $\gamma$-cyclodextrin promotes polymer-polymer intermolecular association in this system even at very low polymer concentrations. ${ }^{32}$ However, in the present study, the absence of interpolymeric interactions with PAAMePy55 was observed. Indeed, as can be seen from Figure 5, for a P123 concentration of $1 \times 10^{-3} \mathrm{M}$, the increase in the PAAMePy55 polymer concentration gives rise to constant $I_{\mathrm{E}} / I_{\mathrm{M}}$ ratio values at $\mathrm{pH}$ 3.6. When intermolecular interactions between PAAMePy55 polymers are present, an increase of the $I_{\mathrm{E}} / I_{\mathrm{M}}$ ratio would be expected. ${ }^{32}$ This fact is also confirmed by the DLS experiments on this system, where no PAAMePy55 interpolymer aggregates were observed at $\mathrm{pH} 3 .^{53}$

Time-Resolved Fluorescence. Time-resolved fluorescence studies previously made on the PAAMePy55 polymer $^{21}$ (and analogous PAAMe naphthalene $\mathrm{e}^{22,23}$ or pyrene $^{31}$ labeled polymers) showed that the decay profiles are fitted to multiexponential decays. The excited-state kinetic behavior is, in these systems, dependent on the probe, probe content, solvent, $\mathrm{pH}$,

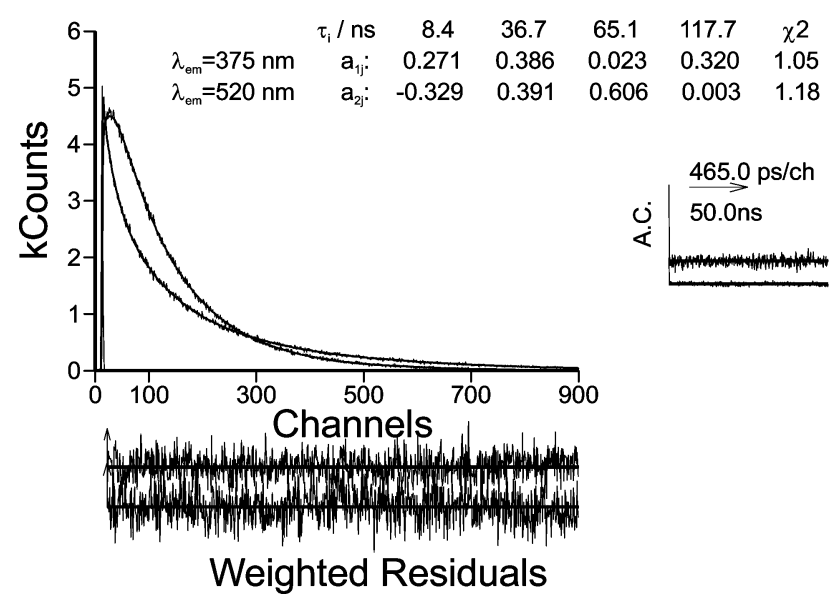

Figure 6. Fluorescence decay of PAAMePy55 in the presence of P123 $\left(C_{\mathrm{P} 123}=1 \times 10^{-6} \mathrm{M}\right)$, at $\mathrm{pH} 3.6$ and at $40^{\circ} \mathrm{C}$, in the monomer $(375$ $\mathrm{nm})$ and in the excimer $(520 \mathrm{~nm})$ emission regions, obtained through global analysis, and excitation wavelength at $339 \mathrm{~nm}$.

temperature, etc. In the simplest situation, ${ }^{21,31}$ the individual analysis of the decays for the monomer and excimer emission wavelength regions are fitted with tri- and biexponential decay laws, respectively, with two common decay times. These two common decay times, $\tau_{2}$ and $\tau_{1}$ (shorter decay time) correspond, respectively, to the emission of monomers that are able to give rise to excimers in the excited-state (abbreviated as MAGRE) (1 $^{21}$ and to the excimer appearing in the monomer emission wavelength as a component associated to the excimer-tomonomer reversibility process. ${ }^{21}$ The additional long lifetime component, present in the monomer decay, has a decay time, identified as $\tau_{0}$, which is connected to the emission of isolated monomers. These monomers are at such a distance that the encounters for excimer formation are not viable. However, as can be seen from the PAAMePy55 fluorescence decays in Figure 6 , in the presence of the P123 block copolymer an additional component, with a decay time $\tau_{3}$, appears at the excimer emission wavelength, corresponding to the emission of a second excimer, not observed in good solvents (for the pyrene probe) such as dioxane or methanol; ${ }^{21,31}$ this was also not identified in our initial studies in water, mainly because as mentioned, the relative contribution of these two excimers is strongly dependent on several conditions (degree of labeling, $\mathrm{pH}$, temperature, etc.). The formation of conformationally different excimers (symmetric and asymmetric sandwich-like excimers) has previously been observed with this polymer in the presence of cyclodextrins $^{32}$ and with analogous pyrene-labeled PAA polymers. ${ }^{31}$

The dependence of the fluorescence decay times and of the preexponential factors with $\log C_{\mathrm{P} 123}$ at $\mathrm{pH} 3.6$, is presented in Figure 7. A general increase of the decay times with the increase in the P123 concentration can be observed. The preexponential factors at the monomer emission wavelength, $a_{10}$ and $a_{11}$, are associated, respectively, with the fraction of isolated excited monomers and MAGRE monomers. ${ }^{21}$ From Figure 7B, it can be observed that $\mathrm{a}_{10}$ increases and $\mathrm{a}_{11}$ decreases with P123, reflecting an increase of the isolated Py monomers in solution with a concomitant decrease of the MAGRE monomers. The preexponential factor value at the excimer emission wavelength associated with $\tau_{1}, a_{21}$, which assumes negative values (Figure 7C), provides extra information to this discussion. Increasing $C_{\mathrm{P} 123}$ gradually leads to a more negative $a_{21}$ preexponential. In line with this, the sum of the $a_{i j}$ preexponentials at the excimer emission wavelength $\left(a_{21}, a_{22}\right.$, and $\left.a_{23}\right)$ gradually changes to less positive values (from water to high P123 concentration). 
TABLE 1: Photophysical Parameters Obtained from the Excitation Spectra for the PAAMePy55-P123 System with Different P123 Concentrations $\left(C_{\mathrm{P} 123}\right)$, at $\mathrm{pH} 3.6$ and $40^{\circ} \mathrm{C}$

\begin{tabular}{lccccccc}
\hline$C_{\mathrm{P} 123} / \mathrm{M}$ & $5 \times 10^{-8}$ & $1 \times 10^{-6}$ & $2 \times 10^{-6}$ & $4 \times 10^{-6}$ & $1 \times 10^{-5}$ & $5 \times 10^{-5}$ & $1 \times 10^{-4}$ \\
\hline$\Delta \lambda_{2}$ & 0.9 & 0.9 & 1 & 0.5 & 0.5 & 0.7 & 0.6 \\
$P_{\mathrm{M}}$ & 2.3 & 2.31 & 2.32 & 2.32 & 2.31 & 2.3 \\
$P_{\mathrm{E}}$ & 1.7 & 1.68 & 1.73 & 1.82 & 1.86 & 1.87 \\
$P_{\mathrm{M}}-P_{\mathrm{E}}$ & 0.60 & 0.63 & 0.59 & 0.49 & 0.44 & 0.44
\end{tabular}
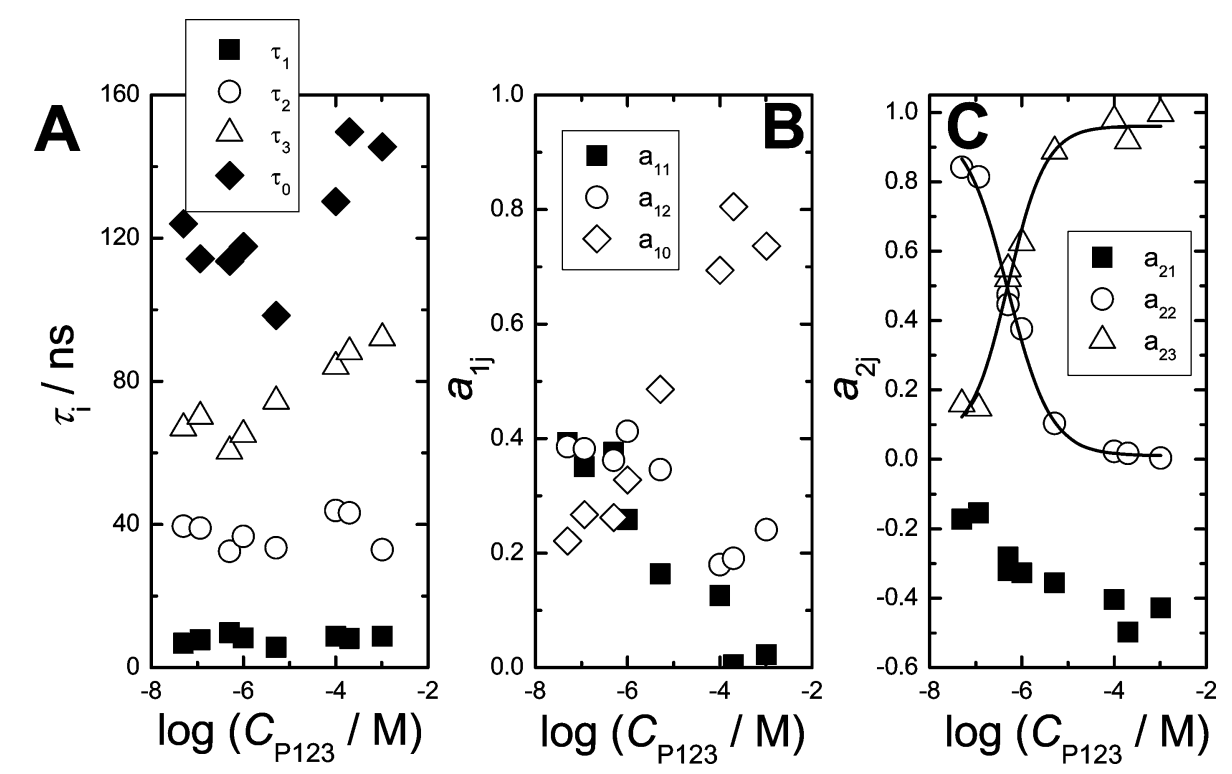

Figure 7. Variation of fluorescence decay times (A) and preexponential factors at the monomer (B) and excimer (C) emission wavelengths with the $\mathrm{P} 123$ concentration, at $\mathrm{pH} 3.6$ and $40^{\circ} \mathrm{C}$. The solid lines are guides to the eye.

The preexponential factors $a_{22}$ and $a_{23}$ are associated to excimers with different geometries: asymmetric (more stable) and symmetric (less stable) sandwich-like, respectively. ${ }^{31,32}$ The gradual addition of P123 leads to a reciprocal behavior of the contribution of these two preexponential factors: a decrease of $a_{22}$ and an increase of $a_{23}$. This suggests that the association between the Py groups and the P123 block copolymer favors the symmetric sandwich-like (less stable) ${ }^{58,59}$ geometry, relative to the twisted sandwich-like geometry.

\section{Discussion}

The following discussion, aimed at the understanding of the interaction between the PAAMePy55 and P123 polymers, will be focused on the changes seen in the absorption, fluorescence spectra (emission and excitation), and decays (time-resolved fluorescence) which are related to the pyrene groups of the PAAMePy55 polymer. As described above, the experimental results show that these changes are affected by the addition of the P123 copolymer.

Absorption and Steady-State Fluorescence Data. At pH 3.6, the segment-segment interactions were found to be dominant, i.e., part of the pyrene chromophores exists in a ground-state associative form. ${ }^{21}$ At the same $\mathrm{pH}$ value, addition of P123 (low and high concentrations, A and B, respectively) leads to changes in the absorption spectra illustrated in Figure 1. For low P123 concentrations, the absorption wavelength maximum $\left(\lambda_{\mathrm{abs}}^{\max }\right)$ is at $\approx 345 \mathrm{~nm}$ and the $P_{\mathrm{A}}$ is $\approx 1.98$; these values are basically identical to those observed without addition of P123. ${ }^{21}$ However, after a certain P123 concentration (Figure 1B), there is a clear blue-shift of the $\lambda_{\mathrm{abs}}^{\max }$ together with an increase in $P_{\mathrm{A}}$. The variation of $P_{\mathrm{A}}$ with $\mathrm{P} 123$, Figure $1 \mathrm{C}$, shows that at a low P123 concentration the $P_{\mathrm{A}}$ values are similar to those found without addition of the copolymer; with the subsequent incremental addition of P123, $P_{\mathrm{A}}$ increases reaching a final value of ca. 2.65. It should be remembered that the $P_{\mathrm{A}}$ parameter reflects the relative ratio of the absorption of monomer and GSD. ${ }^{21}$ Consequently and based on these observations, it can be concluded that a decrease of GSD absorption is promoted by the association of the PAAMePy55 polymer and the P123 block copolymer. Nevertheless, the $P_{\mathrm{A}}$ values are still well below the values generally considered to be indicative for the absence of GSD $\left(P_{\mathrm{A}} \approx 3\right){ }^{21,57,60}$ This demonstrates that GSD exist over the whole $\mathrm{P} 123$ concentration range.

Similar conclusions could be drawn from the emission spectra collected at different excitation wavelengths (Figure 3 ) and from the comparison of the excitation spectra (collected at the monomer and excimer emission wavelengths), Figure 4. ${ }^{21,31}$ The addition of P123 leads to a decrease in the differences between the two excitation spectra, which are measured in terms of the $\Delta \lambda_{2}$ and $P_{\mathrm{M}}-P_{\mathrm{E}}$ parameters (Table 1 ). The $I_{\mathrm{E}} / I_{\mathrm{M}} v s C_{\mathrm{P} 123}$ plots, obtained at different excitation wavelengths (Figure 3 ), give support to this trend of the $P_{\mathrm{M}}-P_{\mathrm{E}}$ and $P_{\mathrm{A}}$ parameters.

The dependence of the $I_{\mathrm{E}} / I_{\mathrm{M}}$ ratio with the P123 concentration, presented in Figure 2B, shows that the two polymers associate; however, the association may occur by two different models. The first involves a cooperative association ${ }^{15}$ between the two polymers, i.e., the Py groups of the PAAMePy55 polymer constitute preferential sites of adsorption of the P123 unimers. In an initial stage, the association is weak since the number of P123 unimers is not large enough to affect the conformation of the PAAMePy55 chain. After a certain concentration, an expansion of the polymer chain and a consequent decrease of the Py-Py attractive interactions are observed. In this case, the PAAMePy55 promotes the micelle formation and a P123 micelle is formed within the former polymer, which implies a decrease of the cmc value of the block copolymer. 
In the second model, the association can occur between the PAAMePy55 polymer and the P123 micelle, i.e., although not completely ruled out, the P123 unimers are not preferentially adsorbed at the PAAMePy55 polymer chain and the P123 micelles are formed free in solution. The association occurs after P123 micelle formation, which is not promoted by the presence of the PAAMePy55 polymer. This implies that the concentration at which changes in the photophysical properties of the PAAMePy55 polymer (decrease of the $I_{\mathrm{E}} / I_{\mathrm{M}}$ ratio) begin to be observed would be equal or higher than the $\mathrm{cmc}$ value of the pure P123 block copolymer.

The cmc of the P123 block copolymer in water was determined by the variation of the $I_{1} / I_{3}$ ratio; see Figure $2 \mathrm{C}$ (inset). The obtained $\mathrm{cmc}$ value was $1.8 \times 10^{-6} \mathrm{M}$. The difference between this $\mathrm{cmc}$ value and those obtained by others with different techniques $\left(3.47 \times 10^{-7} \text { and } 5.2 \times 10^{-7} \mathrm{M}\right)^{42,43,46}$ are most likely related with the different sample batches with different polydispersities. The presence of a small degree of more hydrophobic components, variable from batch to batch, is also likely to affect the obtained cmc values. ${ }^{61}$ Comparing the cmc value of the P123 with the concentration at which the attractive interaction between the P123 and PAAMePy55 polymers begins $\left(3.5 \times 10^{-6}\right.$ and $6.7 \times 10^{-6} \mathrm{M}$, at $\mathrm{pH} 3.6$ and 5 , respectively), one can conclude that the second model of association fits better with our results.

Water is considered a bad solvent for the Py groups of the PAAMePy55 polymer and intra $\mathrm{Py}-\mathrm{Py}$ hydrophobic interactions are more favorable than $\mathrm{Py}-$ solvent interactions. ${ }^{21}$ Due to the hydrophobic interactions, within the PAA chain, the PAAMePy55 polymer adopts a very compact conformation and the environment felt by the pyrene groups is rather hydrophobic when compared with water. ${ }^{21}$ In the low P123 concentration regime, the $I_{1} / I_{3}$ ratio is kept constant and similar to that found in pure water, i.e, the $I_{1} / I_{3}$ ratio is $\sim 1.62$ and $\sim 1.58$, at $\mathrm{pH} 3.6$ and 5, respectively (see Figure $2 \mathrm{C}$ ). In the high P123 concentration regime, the $I_{1} / I_{3}$ reaches a new plateau with a value of $\sim 1.75$, showing an increase of the polarity probed by the Py chromophore. This value is significantly different from that obtained when Py is located inside the P123 micelle core $\left(I_{1} / I_{3}\right.$ $\sim 1.32$; see inset of Figure 2C) which suggests that the Py groups of the PAAMePy55 polymer do not penetrate deeply inside the core of the P123 micelle.

To get more insight on the location of the pyrene groups [attached to the PAA chain] in the P123 micelle, the $I_{1} / I_{3}$ ratio was obtained for pyrene in poly(ethylene oxide) $\left(\mathrm{PEO}, M_{\mathrm{n}}=\right.$ $200 \mathrm{~g} / \mathrm{mol}$ ) and poly(propylene oxide) (PPO, $\left.M_{\mathrm{n}}=1000 \mathrm{~g} / \mathrm{mol}\right)$. $I_{1} / I_{3}$ ratios of 1.74 and 1.03 were obtained in PEO and PPO, respectively, at $40{ }^{\circ} \mathrm{C}$. Although the PEO used is not entirely representative of the system under investigation here, we observe that the values are in very good proximity to those obtained at the high P123 concentration regime. This constitutes an indication that the pyrene groups are located at the PPO/PEO interface of the P123 micelle, where water is abundant. The Py groups of the PAAMePy55 polymer prefer to be in a PPO environment; however, they must follow the PAA chains, and for them, PEO is a better solvent than PPO. Thus, to move the pyrene groups from the hydrophobic environment of the compact coil to the more hydrophilic environment of the P123 block copolymer micelle, an excess of micelles is required and that explains why the concentration of the PAAMePy55 polymer-P123 complex formation is higher than the cmc of the pure P123 block copolymer.

One can also observe that an increase of the $\mathrm{pH}$ (from 3 to 5) revealed an increase in the concentration for the PAAMePy-
P123 complex formation. This observation indicates that the more expanded nature of conformation acquired by the PAA chain does not favor the polymer-micelle association. Similar types of associations have been reported in systems involving PAA polymers and nonionic surfactants ${ }^{62-65}$ and poly(ethylene oxide) polymers. ${ }^{49,50,66,67}$ The formation of interpolymer complexes in these systems has been attributed to hydrogen bonding and hydrophobic effects, with association dependent on the $\mathrm{pH}$ and molecular weight of the two polymers..$^{49,50,62-66}$ Other studies have revealed that a decrease of the $\mathrm{pH}$ and an increase of the molecular weight favors the formation of these type of complexes. ${ }^{49,50,64,66}$ Regarding the role of these interactions, it has been demonstrated that hydrogen bonding is not driving association in an environment with a large excess of water. ${ }^{68}$ Water is a strongly cohesive solvent due to the strong hydrogen bonding between the different water molecules, and any perturbation of this is unfavorable. Therefore, with excess water present, other hydrogen-bonding agents cannot easily compete. The strong preference for water-water interaction makes water "pushing" most other nonionic cosolutes out of water, onto surfaces, into complexes or into a separate phase. A recent conformational study on the influence of the $\mathrm{pH}$ on a conjugated annealed polyelectrolyte showed two conformational transitions; the lowering of the $\mathrm{pH}$ changes the polyelectrolyte conformation from stretched to a collapsed state followed by a densely collapsed state. ${ }^{69}$ The first step of the transition was attributed to the transition from a hydrophilic to a hydrophobic state due to protonation of the carboxylic groups, but we believe that a more important factor is the reduction of osmotic swelling due to the counterions. The second step was promoted by the more hydrophobic character on formation of hydrogen bonds within the "hydrophobic" environment of collapsed chain, which leads to an even more compact conformation. Consequently, the appropriate explanation for complex formation in PAA and nonionic surfactant or polymer systems rely on the hydrophobic interactions, which can be weak per monomer unit but become significant for a high molecular weight polymer. Nevertheless, hydrogen bonding interactions play an important role on the stabilization and strengthening of the formed complex.

In the present study, at acidic $\mathrm{pH}$ values, when the $\mathrm{P} 123$ block copolymer micelle is formed in solution, it is attracted through hydrophobic interaction forces to the PAAMePy55 chain. Since the carboxylic groups are fully protonated, the PAAMePy55 is highly flexible and it covers the P123 micelles. The complex formation is thus governed by the hydrophobic interaction, and once the polymers are at close proximity, hydrogen bonding between the PEO ether groups, of the P123 micelle corona, and the carboxyl groups, of PAAMePy55, may appear. By increasing the $\mathrm{pH}$ of the medium ( $\mathrm{pH} 5)$, a decrease in the level of association between the two polymers is observed. Even though the increase in the $\mathrm{pH}$ will weaken hydrogen bonding, the decrease in the level of association is related with the osmotic swelling effect, i.e., the stretching of the polymer chains and consequent decrease of the PAA chain flexibility. At $\mathrm{pH} 9$, the $I_{\mathrm{E}} / I_{\mathrm{M}}$ ratio was found to be, within the $C_{\mathrm{P} 123}$ range studied, constant which indicates little or absence of association at alkaline $\mathrm{pH}$ values. From the literature on the intercomplex formation between PEO and PAA, ${ }^{47-50,70}$ we may expect that the association between PAAMePy55 and P123 decreases at high $\mathrm{pH}$. An earlier light scattering study has been performed on the interaction between PAA and PEO-PPO-PEO copolymers also showed that they associate at low and intermediate $\mathrm{pH}$ values but not at high $\mathrm{pH} \cdot{ }^{71}$ However, in our specific case, the PAA chain has some pyrene groups attached which might 
help in stabilizing the PAAMePy55-P123 complex even at high $\mathrm{pH}$ (see above the $I_{1} / I_{3}$ pyrene variation), contrary to which has been observed with the unlabeled PAA. ${ }^{67}$ Monte Carlo simulations on the effect of the polyelectrolyte chain flexibility in its interaction with charged micelles ${ }^{72}$ showed that in the case of a flexible chain the polyelectrolyte is entirely adsorbed at the micelle surface. Increasing the chain rigidity, the polyelectrolyte has more difficulties to be close to the micelle, and only a few segments are in close contact with the micelles. Although this study was performed with a polyelectrolyte and a positively charged micelle, it can explain the present results since an increase in the $\mathrm{pH}$ results in an increase in the PAA chain rigidity. As a consequence, at $\mathrm{pH} 9$ the PAA chain adopts a very rigid and expanded conformation strongly diminishing the degree of association with the P123 block copolymer micelles. This implies that only a few pyrene groups are in close contact with the P123 micelles, i.e., at alkaline $\mathrm{pH}$ values the conformation adopted by the PAAMePy55 is only slightly affected by the association with the P123 micelles. The DLS measurements, recently performed on the same system, are difficult to interpret since they are not conclusive about the possibility for complex formation at $\mathrm{pH} 9 .{ }^{53}$ The PAAMePy55 chains that diffuse collectively and appear as large domains in the pure polyelectrolyte system without P123 are still observable in the DLS results of the mixed system at $\mathrm{pH} 9$ together with free P123 micelles. This means that these domains may contain a few entrapped P123 micelles. However, there is also another possible explanation. The $\mathrm{PEO}-\mathrm{PPO}-\mathrm{PEO}$ copolymers are polydisperse both in mass and chemical composition. The association observed in the fluorescence data may then originate from the fact that PEO-PPO-PEO copolymer samples contain diblock PEO-PPO copolymers (impurities). Recent studies by Hvidt et al. have shown that hydrophilic impurities (with a high PEO content) may exist in solution and that they are not involved in the PEO-PPO-PEO micelle formation. ${ }^{73,74}$ Hence, the interaction between the PEO blocks of these impurities and the pyrene groups of the PAAMePy55 chain would then be reflected in the fluorescence $I_{1} / I_{3}$ data (see below) but not in the DLS data. This is further discussed in ref 53. The purification of the P123 sample will be necessary in order to distinguish between these two scenarios.

It is also noteworthy that different $I_{\mathrm{E}} / I_{\mathrm{M}}$ ratios were obtained in the low P123 concentration regime. Prior to the P123 micelle formation, the PAAMePy55 polymer chain conformation is ruled by the balance between the hydrophobic and electrostatic repulsive forces. At low $\mathrm{pH}$, the former dominate and a compact conformation is obtained with most of the pyrene groups in the ground-state associative form (high $I_{\mathrm{E}} / I_{\mathrm{M}}$ ratio). When increasing the $\mathrm{pH}$, the $\mathrm{Py}-\mathrm{Py}$ attractive interactions compete with the additional repulsive interactions, between the deprotonated carboxylic $\left(\mathrm{COO}^{-}\right)$groups and the polymer chain expands (the $I_{\mathrm{E}} / I_{\mathrm{M}}$ ratio decreases). However, when the PAAMePy55 polymer starts to associate with the P123 micelles additional competitive hydrophobic interactions start to come into play, i.e., $\mathrm{Py}-\mathrm{PPO}$ and $\mathrm{PPO}-\mathrm{PPO}$ interactions compete with the $\mathrm{Py}-\mathrm{Py}$ interactions and a further expansion of the PAA polymer chain is observed at $\mathrm{pH} 3.6$ and 5, i.e., the $I_{\mathrm{E}} / I_{\mathrm{M}}$ ratio decreases and reaches similar values in the high $\mathrm{P} 123$ concentration regime at both $\mathrm{pH}$ values (see Figure 2B).

Time-Resolved Fluorescence. Figure 7 shows the tendency of variation of the parameters $\left(a_{i j}\right.$ and $\left.\tau_{i}\right)$ taken from the fluorescence decays collected at the monomer and excimer emission wavelengths. All the obtained data is in agreement with the formation of a P123 micelle attached to the PAAMe-

\section{SCHEME 2}

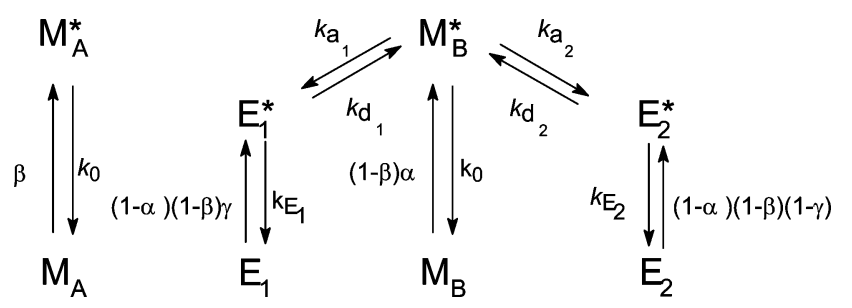

\section{SCHEME 3}

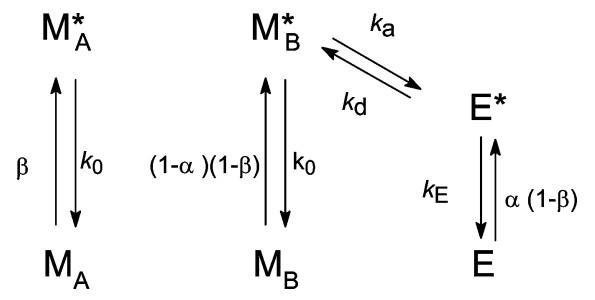

Py55 polymer chain where the Py groups are located at the PPO/ PEO interface of the P123 micelle, i.e., in contact with the PEO corona of the micelle. In fact, the increase of the obtained decay times with the gradual increase of the P123 concentration suggests that the Py is probing a different environment. Studies in aqueous solution and in a poly(ethylene oxide) melt showed a decrease in the amount of dissolved oxygen when the solvent is changed from bulk water to melt poly(ethylene oxide) $(0.29$ $\times 10^{-3}$ and $0.12 \times 10^{-3} \mathrm{~mol} / \mathrm{L}$, respectively, at $293 \mathrm{~K}$ and 0.21 atm). ${ }^{75}$ In agreement with these findings, the formation of P123 micelles surrounded by the PAAMePy55 polymer decreases the encounter between the Py groups and oxygen (fluorescence quencher),${ }^{76}$ which leads to an increase of the decay time values with the $C_{\mathrm{P} 123}$.

The variation of the preexponential factors associated with each decay time also provides information concerning the intramolecular distances between the Py groups at the PAAMePy55 polymer chain. The increase of the P123 concentration in solution leads to an increase of the isolated monomers (growth of $\left.a_{10}\right)$ at the expense of the decrease of the MAGRE monomers ( $a_{11}$ decreases). On the other hand, the sum of the preexponential factors at the excimer emission wavelength $\left(a_{21}, a_{22}\right.$, and $\left.a_{23}\right)$ is always positive, although with increasing P123 concentration it approaches the zero value. This confirms the increase in the intra Py-Py distance and also the coexistence of static and dynamic excimer formation; the latter gains weight over the former with $C_{\mathrm{P} 123}$. Nevertheless, since the sum of the $a_{21}, a_{22}$, and $a_{23}$ preexponentials never reaches the value zero; this indicates that GSD are present at all P123 concentrations. ${ }^{21}$

As a consequence of all of the above, the kinetic Scheme 2, observed in the present study, is identical to that proposed in refs 31 and 32, and under certain circumstances (methanol or dioxane, etc.), it can be simplified to Scheme $3 .^{21,31}$ In this scheme, $\beta$ stands for the fraction of light exciting the isolated monomers, $\mathrm{M}_{\mathrm{A}} ; \alpha(1-\beta)$ the fraction of light used to excite the MAGRE chromophores, $\mathrm{M}_{\mathrm{B}}$; and $(1-\alpha)(1-\beta)$ the fraction of light absorbed by $\mathrm{E}_{1}$ (asymmetric excimer) and $(1-\alpha)(1-$ $\beta)(1-\gamma)$ by $\mathrm{E}_{2}$ (symmetric excimer). ${ }^{31}$ Also in Scheme 2 , the rate constants are defined as follows: $k_{\mathrm{a} i}$, rate constant for excimer formation (with $i=1,2$ for the formation of excimer $\mathrm{E}_{1}$ and $\mathrm{E}_{2}$, respectively); $k_{\mathrm{d} i}$, rate constant for excimer dissociation; $k_{\mathrm{M}}=1 / \tau_{\mathrm{M}}$ and $k_{\mathrm{E} i}=1 / \tau_{\mathrm{E} i}$, reciprocals of the unquenched lifetimes of the monomer and excimer, i.e., the rate constants for monomer and excimer radiative and radiationless decay.

The degree of GSD dimers can be quantitatively estimated by the determination of the $(1-\alpha)(1-\beta) \gamma$ and $(1-\alpha)(1-$ 
TABLE 2: Fluorescence Parameters, i.e. the Fluorescence Decay Times $\left(\tau_{i}\right)$ and the Normalized Amplitudes $\left(a_{i 1}, a_{i 2}, a_{i 3}\right.$, and $a_{i 0}$ with $i=1,2)$, Taken from the Individual Analyses of the Fluorescence Decays of the PAAMePy55 Polymer with Different Concentrations of $\mathrm{P123}$, at $\mathrm{pH} 9$ and $40{ }^{\circ} \mathrm{C}^{a}$

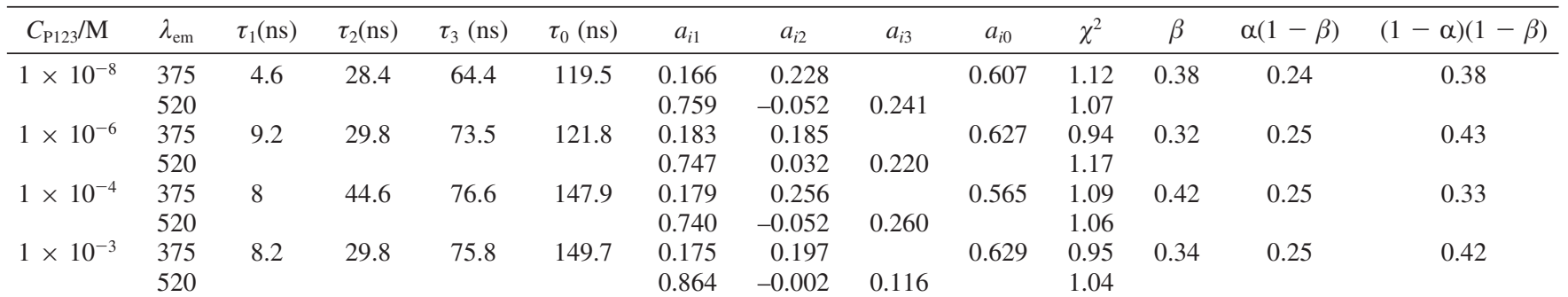

${ }^{a}$ The fraction of light that excites free monomers $(\beta)$, MAGRE monomers $[(1-\alpha)(1-\beta)]$, and dimers $[\alpha(1-\beta)]$ determined through the resolution of kinetic Scheme 3 is also presented.

$\beta)(1-\gamma)$ factors in Scheme 2. Although the complete solution of the kinetic Scheme 2 is presently under investigation, an important factor, resulting from the present study, is the possibility to quantify the effect of P123 addition on the level of ground-state association within the PAA chain. In order to get more insight on the level of association between the P123 and PAAMePy55 polymers, the kinetic Scheme 2 can be simplified by assuming that the contributions from $\mathrm{E}_{1}$ and $\mathrm{E}_{2}$ are from a single and generic excimer, E. In this case, the triand biexponential decay fits at the monomer and excimer emission wavelengths are assumed to describe the PAAMePy55 polymer in water ${ }^{21}$ with the decay time and preexponetial factor associated to the excimer, E, merging the contribution of the two excimers, $E_{1}$ and $E_{2}$. This is then reflected by Scheme 3 .

The validity of this assumption lies in the fact that for the purposes of evaluation of the level of existent GSD, the geometry type of the formed excimer is not relevant. In fact, it could be the case that one of the excimers $\left(E_{1}\right.$ or $\left.E_{2}\right)$ is nonexisting in the ground-state and is only formed in the excitedstate at the expense of the monomer decay. This, however, cannot be inferred by the present data.

As a result of this simplified kinetic Scheme 3, a single type of excimer may be considered. This has a decay time which results from the average values of $\tau_{2}$ and $\tau_{3}$ and the fraction of light exciting each species. This in turn gives the concentration of each species at time zero, isolated Py monomers $(\beta), M A G R E$ $[(1-\alpha)(1-\beta)]$ monomers and ground-state dimers (with asymmetric and symmetric geometries) $[\alpha(1-\beta)]$. In the absence of $\mathrm{P} 123$, the $\beta,(1-\alpha)(1-\beta)$, and $\alpha(1-\beta)$ values obtained in Scheme 3 are, respectively, 0.15, 0.34, and 0.51. In the low P123 concentration regime, these values are kept approximately constant. In the high P123 concentration regime, the $\beta,(1-\alpha)(1-\beta)$, and $\alpha(1-\beta)$ values are instead 0.7 , 0.25 , and 0.05 , respectively. This shows that the fraction of light that excites the ground-state dimers is reduced by $90 \%$ while the fraction of light that excites the MAGRE monomers is reduced only by ca. $25 \%$. The decrease of the excimer formation is essentially made at the expense of a decrease in the level of GSD, which results from the association with P123 micelles promoting an increase in the intrapolymer distance between adjacent pyrene groups. Also as a result of this association and of the PAA chain expansion, the main emissive species are now the isolated Py monomers.

In short, from the time-resolved fluorescence data there is clear evidence that the pyrene labeled PAA and the P123 block copolymer associate at low $\mathrm{pH}$ and that the interaction results in an expansion of the PAA chain, which is promoted by the formation of a P123 micelle.

The fluorescence decay parameters obtained at $\mathrm{pH} 9$ for the PAAMePy55 polymer in the presence of $\mathrm{P} 123$ are presented in
Table 2. The $a_{i j}$ preexponential factors at both emission wavelengths and the determined fractions of light that excite each species can be considered constant with P123 concentration within the experimental error, in agreement with the steadystate data presented in Figure 2B. However, there is a tendency for an increase of the decay time values with P123 concentration. The decay time $\tau_{0}$ increases to values similar to those found at acidic $\mathrm{pH}$ values, which is a further indication that the pyrene groups of the PAA are in contact with the poly(ethylene oxide) blocks of the P123 block copolymers, since it decreases the encounter between the Py groups and oxygen, as mentioned above.

The overall data suggest the formation of P123 micelles that associates with the pyrene groups of the PAA polymer; this association, although strongly reduced when compared with the interaction at acidic $\mathrm{pH}$ values, still occurs at alkaline $\mathrm{pH}$. The observed interaction at high $\mathrm{pH}$ values may also be a reflection of the known heterogeneity of this PEO-PPO-PEO copolymer. ${ }^{74}$ The above results (absorption, steady-state, and timeresolved fluorescence) show clearly that the association between the PAAMePy55 and the P123 block copolymer results in the complex formation of several P123 micelles surrounded by one PAAMePy55 chain at acidic $\mathrm{pH}$. However, the number of contacts between the PAAMePy55 chain and the P123 micelles, i.e., the number of pyrene groups inserted into the P123 micelles gradually decreases with increasing the $\mathrm{pH}$ due to a decrease of the PAAMePy55 chain flexibility.

A detailed DLS study to further explore the complex formation and association behavior between PAAMePy55 and P123 at different $\mathrm{pH}$ values (3, 5, and 9) including the determination of the hydrodynamic radius of the PAAMePy55-P123 complex at low $\mathrm{pH}$ will be presented in a forthcoming work. ${ }^{53}$

\section{Conclusions}

The interaction between the PAA hydrophobically modified with pyrene, PAAMePy55, and the block copolymer P123 was studied using fluorescence techniques. The fluorescence studies allowed the determination of the concentration at which the presence of the P123 block copolymer affects the PAAMePy55 photophysical properties. It was found that this concentration is higher than the cmc of the pure P123 block copolymer, i.e., the latter polymer does not promote the P123 micellization process leading to a conclusion that micelle formation occurs in water and it is then surrounded by the PAAMePy55 polymer chain, with the pyrene groups of the latter located at the PPO/ PEO interface of the block copolymer micelle. The interaction is reflected by a decrease of the $I_{\mathrm{E}} / I_{\mathrm{M}}$ ratio, as well as by an increase of the number of isolated pyrene monomers, a decrease of MAGRE monomers in solution and an increase of the 
hydrodynamic radius, i.e., by an expansion of the polymer chain. The association between the two amphiphilic polymers becomes progressively more unfavorable with increasing $\mathrm{pH}$, which is mirrored by an increase of the concentration value at which the complex is formed when the $\mathrm{pH}$ increases from 3.6 to 5 . At alkaline $\mathrm{pH}$ values, no variation of the $I_{\mathrm{E}} / I_{\mathrm{M}}$ ratio was observed; however, the $I_{1} / I_{3}$ ratio and the decay times obtained through the fluorescence decays indicate that minor association between PAAMePy55 and P123 still occurs. This could either be a reflection of the fact that in spite of the lower flexibility of the PAAMePy55 chain it can associate with the P123 micelles or the fact that unassociated hydrophilic diblock PEO-PPO copolymers are present in the solution and interact with the PAAMePy55 chains.

This fluorescence study has shown that there are two main factors that influence the complex formation between PAAMePy55 and P123: the hydrophobicity and the flexibility of the PAAMePy55 chain. The former is the driving force of the interaction. Although hydrogen bonds (between the protonated carboxylic groups of the PAA chains and the ether oxygens of the PEO blocks of the P123 block copolymers) are likely to be formed, it is most reasonable to consider that they will not be the driving force for the interaction but rather a consequence of the close proximity between the two polymers. The latter determines the extension of the interaction, i.e., decreasing the flexibility of the PAAMePy55 chain (observed on increasing the $\mathrm{pH}$ ) the interaction becomes progressively less and less viable, due to the fact the PAAMePy55 polymer chain is not able to surround the P123 micelles, thus the number of pyrene and/or carboxylic groups involved in the complex formation are reduced. Further information about the PAAMePy55-P123 interaction and complex formation are provided from dynamic light scattering measurements. ${ }^{53}$

Acknowledgment. Financial support from the Portuguese Science Foundation (projects POCI/QUI/58689/2004 and PTDC/ QUI/67962/2006), the Swedish Research Council (VR), and the Linnaeus Center of Excellence "Organizing Molecular Matter" is acknowledged. T.C. acknowledges FCT for a Ph.D. grant (SFRH/BD/17852/2004).

\section{References and Notes}

(1) Thuresson, K.; Lindman, B.; Nyström, B. J. Phys. Chem. B 1997, 101,6450 .

(2) Anghel, D. F.; Alderson, V.; Winnik, F. M.; Mizusaki, M.; Morishima, Y. Polymer 1998, 39, 3035.

(3) Schillén, K.; Anghel, D. F.; Miguel, M. D.; Lindman, B. Langmuir 2000, 16, 10528.

(4) Farinha, J. P. S.; Piçarra, S.; Miesel, K.; Martinho, J. M. G. J. Phys. Chem. B 2001, 105, 10536.

(5) Deo, P.; Jockusch, S.; Ottaviani, M. F.; Moscatelli, A.; Turro, N. J.; Somasundaran, P. Langmuir 2003, 19, 10747.

(6) Miyazawa, K.; Winnik, F. M. J. Phys. Chem. B 2003, 107, 10677.

(7) Relógio, P.; Martinho, J. M. G.; Farinha, J. P. S. Macromolecules 2005, 38, 10799.

(8) Thuresson, K.; Söderman, O.; Hansson, P.; Wang, G. J. Phys. Chem. 1996, $100,4909$.

(9) Wang, Y. L.; Han, B. X.; Yan, H. K.; Kwak, J. C. T. Langmuir $1997,13,3119$.

(10) Piculell, I.; Thuresson, K.; Lindman, B. Polym. Adv. Technol. 2001, 12,44 .

(11) Bai, G. Y.; Nichifor, M.; Lopes, A.; Bastos, M. J. Phys. Chem. B 2005, 109, 21681.

(12) Nishikawa, T.; Akiyoshi, K.; Sunamoto, J. J. Am. Chem. Soc. 1996, 118,6110 .

(13) Greminger, G. K., Krumel, K. L. In Handbook of Water-Soluble Gums and Resins; Davidson, R. L., Ed.; McGraw-Hill Book Company: New York, 1980.

(14) Shaw, K. G.; Leipold, D. P. J. Coat. Technol. 1985, 57, 63.
(15) Holmberg, K., Jönsson, B., Kronberg, B., Lindman, B. Surfactants and Polymers in Aqueous Solution, 2nd ed.; John Wiley \& Sons, Ltd: West Sussex, 2003.

(16) Evertsson, H.; Nilsson, S. Carbohydr. Polym. 1999, 40, 293.

(17) Maiti, S.; Jayachandran, K. N.; Chatterji, P. R. Polymer 2001, 42, 7801.

(18) Anghel, D. F.; Toca-Herrera, J. L.; Winnik, F. M.; Rettig, W.; von Klitzing, R. Langmuir 2002, 18, 5600.

(19) Panmai, S.; Prud'homme, R. K.; Peiffer, D. G.; Jockusch, S.; Turro, N. J. Langmuir 2002, 18, 3860.

(20) Piçarra, S.; Duhamel, J.; Fedorov, A.; Martinho, J. M. G. J. Phys. Chem. B 2004, 108, 12009.

(21) Seixas de Melo, J.; Costa, T.; Miguel, M. G.; Lindman, B.; Schillén, K. J. Phys. Chem. B 2003, 107, 12605.

(22) Costa, T.; Miguel, M. G.; Lindman, B.; Schillén, K.; Lima, J. C.; Seixas de Melo, J. J. Phys. Chem. B 2005, 109, 3243.

(23) Costa, T.; Miguel, M. G.; Lindman, B.; Schillén, K.; Seixas de Melo, J. S. J. Phys. Chem. B 2005, 109, 11478.

(24) Piçarra, S.; Relógio, P.; Afonso, C. A. M.; Martinho, J. M. G.; Farinha, J. P. S. Macromolecules 2003, 36, 8119.

(25) Sarrazincartalas, A.; Iliopoulos, I.; Audebert, R.; Olsson, U. Langmuir 1994, 10, 1421.

(26) Wu, S. H.; Shanks, R. A.; Bryant, G. J. Appl. Polym. Sci. 2006, 100,4348

(27) Principi, T.; Goh, C. C. E.; Liu, R. C. W.; Winnik, F. M. Macromolecules 2000, 33, 2958.

(28) Hait, S. K.; Majhi, P. R.; Blume, A.; Moulik, S. P. J. Phys. Chem. B 2003, 107, 3650.

(29) Kaafarani, B. R.; Wex, B.; Strehmel, B.; Neckers, D. C. Photochem. Photobiol. Sci. 2002, 1, 942.

(30) Miguel, M. d. G. Adv. Colloid Interface Sci. 2001, 89, 1.

(31) Seixas de Melo, J.; Francisco, A.; Costa, T.; Maçanita, A.; Gago, S.; Gonçalves, I. S. Phys. Chem. Chem. Phys. 2007, 9, 1370.

(32) Seixas de Melo, J.; Costa, T.; Oliveira, N.; Schillén, K. Polym. Int. 2007, 56, 882 .

(33) Valeur, B. In Molecular Luminescence Spectroscopy. Methods and Applications: Part 3; Schulman, S. G., Ed.; Wiley-Interscience: New York, 1993; p 25.

(34) Alexandridis, P.; Holzwarth, J. F.; Hatton, T. A. Macromolecules 1994, 27, 2414.

(35) Beezer, A. E.; Loh, W.; Mitchell, J. C.; Royall, P. G.; Smith, D. O.; Tute, M. S.; Armstrong, J. K.; Chowdhry, B. Z.; Leharne, S. A.; Eagland, D.; Crowther, N. J. Langmuir 1994, 10, 4001.

(36) Linse, P.; Malmsten, M. Macromolecules 1992, 25, 5434.

(37) Brown, W.; Schillén, K.; Hvidt, S. J. Phys. Chem. 1992, 96, 6038.

(38) Brown, W.; Schillén, K.; Almgren, M.; Hvidt, S.; Bahadur, P. J. Phys. Chem. 1991, 95, 1850.

(39) Karlström, G. J. Phys. Chem. 1985, 89, 4962.

(40) Jansson, J.; Schillén, K.; Nilsson, M.; Söderman, O.; Fritz, G.; Bergmann, A.; Glatter, O. J. Phys. Chem. B 2005, 109, 7073.

(41) Löf, D.; Niemiec, A.; Schillén, K.; Loh, W.; Olofsson, G. J. Phys. Chem. B 2007, 111, 5911 .

(42) Jansson, J.; Schillén, K.; Olofsson, G.; da Silva, R. C.; Loh, W. J. Phys. Chem. B 2004, 108, 82.

(43) da Silva, R. C.; Olofsson, G.; Schillén, K.; Loh, W. J. Phys. Chem. B 2002, 106, 1239.

(44) Löf, D.; Schillén, K.; Torres, M. F.; Müller, A. J. Langmuir 2007, 23, 11000 .

(45) Schillén, K.; Jansson, J.; Löf, D.; Costa, T. J. Phys. Chem. B 2008, 112,5551 .

(46) Wanka, G.; Hoffmann, H.; Ulbricht, W. Macromolecules 1994, 27, 4145.

(47) Bailey, F. E.; Lundberg, R. D.; Callard, R. W. J. Polym. Sci. Part A-Gen. Pap. 1964, 2, 845.

(48) Tsuchida, E.; Abe, K. Advan. Polym. Sci. 1982, 45, 1.

(49) Khutoryanskiy, V. V.; Dubolazov, A. V.; Nurkeeva, Z. S.; Mun, G. A. Langmuir 2004, 20, 3785.

(50) Khutoryanskiy, V. V.; Mun, G. A.; Nurkeeva, Z. S.; Dubolazov, A. V. Polym. Int. 2004, 53, 1382.

(51) Baranovsky, V.; Petrova, T.; Rashkov, I. Eur. Polym. J. 1991, 27, 1045 .

(52) Sivadasan, K.; Somasundaran, P.; Turro, N. J. Colloid Polym. Sci. 1991, 269, 131.

(53) Costa, T.; Seixas de Melo, J.; Miguel, M. d. G.; Lindman, B.; Schillén, K. J. Phys. Chem. B 2009, 113, 6205.

(54) Seixas de Melo, J.; Fernandes, P. F. J. Mol. Struct. 2001, 565, 69.

(55) Striker, G.; Subramaniam, V.; Seidel, C. A. M.; Volkmer, A. J. Phys. Chem. B 1999, 103, 8612.

(56) Dong, D. C.; Winnik, M. A. Can. J. Chem.-Rev. Can. Chim. 1984, 62,2560

(57) Winnik, F. M. Chem. Rev. 1993, 93, 587.

(58) Zachariasse, K. A.; Duveneck, G.; Kühnle, W. Chem. Phys. Lett. $1985,113,337$. 
(59) Zachariasse, K. A., Duveneck, G., Kühnle, W., Leinhos, U. Reynders, P. In Photochemical Processes in Organized Molecular Systems; Honda, K., Ed.; North-Holland: Amsterdam, 1991; p 83.

(60) Kanagalingam, S.; Ngan, C. F.; Duhamel, J. Macromolecules 2002, 35,8560 .

(61) Zana, R. In Amphiphilic Block Copolymers. Self-Assembly and Applications; Alexandridis, P., Lindman, B., Eds.; Elsevier Science: Amsterdam, 2000; p 221.

62) D’Errico, G.; Ciccarelli, D.; Ortona, O.; Paduano, L.; Sartorio, R.

J. Colloid Interface Sci. 2004, 270, 490.

63) Robb, I. D.; Stevenson, P. Langmuir 2000, 16, 7168

(64) Anghel, D. F.; Saito, S.; Baran, A. Langmuir 1998, 14, 5342.

(65) Vasilescu, M.; Anghel, D. F.; Almgren, M.; Hansson, P.; Saito, S. Langmuir 1997, 13, 6951.

(66) Heyward, J. J.; Ghiggino, K. P. Macromolecules 1989, 22, 1159. (67) Koussathana, M.; Lianos, P.; Staikos, G. Macromolecules 1997, 30,7798 .
(68) Dias, R. S.; Lindman, B. DNA Interactions with polymers and surfactants; Wiley-Blackwell: Hoboken, NJ, 2008.

(69) Vallat, P.; Catala, J.-M.; Rawiso, M.; Schosseler, F. EPL 2008, $82,28009$.

(70) Vasheghani, B.; Rajabi, F. H.; Ahmadi, M. H.; Nouhi, S. Polym. Bull. 2006, 56, 395. 421.

(71) Cole, M. L.; Whateley, T. L. J. Colloid Interface Sci. 1996, 180,

(72) Wallin, T.; Linse, P. Langmuir 1996, 12, 305.

(73) Batsberg, W.; Ndoni, S.; Trandum, C.; Hvidt, S. Macromolecules 2004, 37, 2965.

(74) Hvidt, S.; Batsberg, W. Int. J. Polym. Anal. Charact. 2007, 12, 13.

(75) Murov, S.; Charmichael, I.; Hug, G. L. Handbook of Photochemistry, 2nd ed.; M. Dekker Inc: New York, 1993.

(76) Seixas de Melo, J. Chem. Educ. 2005, 10, 29.

JP8093879 